\title{
Sensory quality of custard tart as affected by varying levels of Mabolo (Dispyros blancoi A. DC) Flesh
}

Loraine P. Baclayon', Julious B. Cerna ${ }^{3}$ and Lynette C. Cimafranca ${ }^{2 *}$

\begin{abstract}
Submitted: 1 October 2019 | Accepted: 9 June 2020

Mabolo (Diospyros blancoi A. DC) is an underutilized fruit in the Philippines. To add value and maximize the utilization of this nutritional fruit, the potential of mabolo for the production of highly saleable baked products, such as tarts, was explored. Specifically, the study aimed to formulate a custard tart filling with mabolo flesh as a flavorant using a single factor experiment arranged in a Completely Randomized Design (CRD). Six levels of mabolo flesh $(0,15,30,45,60$, \& $75 \% \mathrm{w} / \mathrm{w}$ ) were used. The sensory attributes for color, taste, aroma, texture, flavor, and general acceptability, were evaluated. The optimum formulation of the tart filling was determined using Regression analysis.

Results showed that mabolo custard tart filling had yellowish-brown to brown color, moderately sweet to sweet taste, and soft to slightly fibrous texture. The mabolo fruit aroma and flavor in the tarts ranged from having none to perceptible. The Analysis of Variance revealed that different levels of mabolo flesh cause a significant effect on the color $(p<0.01)$. The optimum formulation and the recommended level of mabolo flesh in custard tart filling production was $80.54 \%$ $w / w$.
\end{abstract}

Keywords: tart filling, mabolo, sensory evaluation, optimization, tart

\section{INTRODUCTION}

Diospyros blancoi A. DC is an indigenous fruit belonging to the Ebenaceae (Ebony) family and is locally called Mabolo (Pobar 2013, Hung et al 2016, Yadav et al 2018). The medium-sized fruit has a skin that turns purple or maroon when ripe and is covered with velvety hairs. The fruit is nutritiously good with a slightly sweet taste and dry texture (Pobar 2013).

'Department of Food Science and Technology, Visayas State University, Baybay City, Leyte

*Corresponding Author. Address: Department of Food Science and Technology, Visayas State University, Baybay City, Leyte; Email: lynette.cimafranca@vsu.edu.ph

DOI: 10.32945/atr4227.2020 


\section{Sensory quality of custard tart as affected by varying levels of Mabolo}

Many of the macro and micronutrients necessary for humans are present in ripe mabolo fruit. Consuming fruits can provide carbohydrates, protein, fiber, and energy. Micronutrients such as vitamin $\mathrm{C}$, vitamin $\mathrm{E}$, sodium, potassium, iron, arsenic $\left(0.01 \mathrm{mg} \mathrm{kg}^{-1}\right)$, calcium, folic acid, pantothenic acid, malic acid, magnesium, phosphorus, zinc, and tannin acid are among the identified compounds contained in mabolo fruits (Hung et al 2016, Haque et al 2009). Mabolo fruit contains various bioactive compounds such as alkaloids, flavonoids, tannins, terpenoids, and essential oils (Maridass et al 2008), which are reported to possess preventive and medicinal properties (Akter et al 2015 as cited by Yadav et al 2018). Despite these beneficial health components in mabolo fruit, utilization of the commodity remains limited and it has minimum to almost no economic use. This may be because the pulp of the mabolo fruit emits a strong cheesy odor when opened possibly deterring consumers. It is often presumed that the fruit has no value; hence no one is interested in the cultivation, enhancement, and propagation of the species. Innovative efforts to transform underutilized and disregarded fruit into a product with high marketability and value are necessary to raise the crop's value. One of the products that are capable of masking the unpleasant and foul cheesy odor is the incorporation of the fruit flesh into highly saleable bakery products (Pobar 2013). One of the easily produced, home baked products visibly seen in the market are tarts.

The tart is defined as a sweet or savory dish with shallow sides and a bottom crust. Usually, tart crusts are made from pastry dough, traditionally made from wheat flour, unsalted butter, cold water, and sugar. Parameters that often affect the quality of tarts are commonly associated with factors such as the quality of the raw materials and the nature of the product. Labor cost, production process, waste of materials, cost of preservation and transportation costs affect the profitability of the product. The production of baked goods requires a number of processing steps between which there exists significant interaction. In terms of quality, the temperature and humidity provide a great impact. The stages of mixing, forming, proofing, baking, and cooling are likewise considered. Aside from the factors mentioned above, the tart filling, which normally dictates variance, may also pose a significant difference in the sensory quality, physical properties and shelf life of the product. Incorporating mabolo flesh, for example, may either cause deteriorative or quality enhancement to the product. Hence, this study aimed to determine the effect of the various levels of mabolo flesh in the filling on the sensory quality of the tart product, as well as to determine the optimum formulation.

\section{MATERIALS AND METHOD}

\section{Procurement of Raw Materials}

Mabolo fruit was collected from the farms of Abuyog, Leyte. All-purpose flour, sugar, butter, milk, and eggs were purchased at the local market in Baybay City, Leyte.

\section{Preparation of Mabolo Fruit}

The trichomes (hair) of the mabolo fruit were rubbed off using a brush and washed thoroughly using tap water. The fruits were pared, sliced into 4 to 6 parts, 
and the seeds were removed. The sliced fruits were steam-blanched for 3 to $5 \mathrm{~min}$ to stop enzymatic reaction or browning. After steam blanching, the fruit slices were cooled, packed into polyethylene (PE) bags, and stored in the freezer before use.

\section{Preparation of the Mabolo Filling}

Frozen mabolo flesh (contained in PE bags) was thawed in running water. It was weighed, and various amounts were added to a custard mixture made of condensed milk $(67.07 \% \mathrm{w} / \mathrm{w})$, eggs $(8.67 \% \mathrm{w} / \mathrm{w})$, butter $(7.45 \% \mathrm{w} / \mathrm{w})$, vanilla $(0.87 \% \mathrm{w} / \mathrm{w})$ and all-purpose flour $(15.94 \% \mathrm{w} / \mathrm{w})$. The different fruit and custard mixtures were cooked in a double boiler. These were then cooled at room temperature for about 5 min before being filled into the pastry boat shells (Figure 1 ).

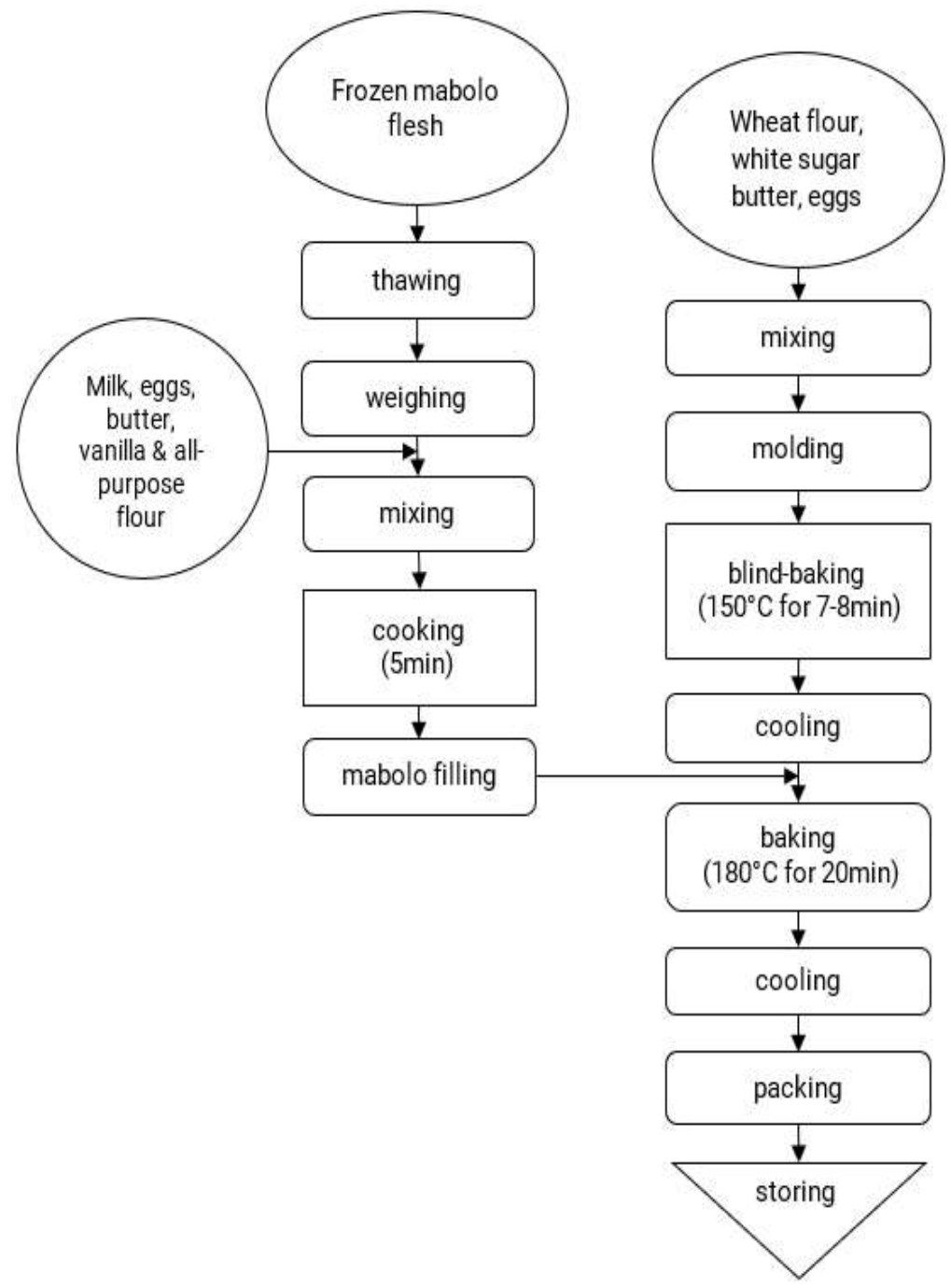

Figure 1. The process flow chart in the production of mabolo tart 


\section{Sensory quality of custard tart as affected by varying levels of Mabolo}

\section{Preparation of the Tart Pastry Shell}

Softened butter $(43 \mathrm{~g})$, eggs $(50 \mathrm{~g})$, white sugar $(250 \mathrm{~g})$, and wheat flour $(250 \mathrm{~g})$ were mixed thoroughly in a clean and sanitized mixing bowl until the tart dough became homogeneous. It was molded into clean, sanitized, and greased tart molders and excess batter was sliced off. Blind-baking at $150^{\circ} \mathrm{C}$ for $7-8 \mathrm{~min}$ followed. They were then allowed to cool at room temperature (Figure 1).

\section{Processing of Mabolo Tart}

The freshly prepared mabolo filling $(20 \mathrm{~g})$ was scooped and spread into each of the prepared boat tart shells. They were then placed inside a preheated oven and baked at $180^{\circ} \mathrm{C}$ for about $20 \mathrm{~min}$. The properly baked tarts were removed from the oven and cooled on a rack. After cooling, the tarts were packed in polyethylene bags and stored in an airtight container before analysis.

\section{Experimental Design}

A single factor experiment arranged in Completely Randomized Design (CRD) was used in this study. The experiment employed six different levels of mabolo flesh in the production of tart fillings. Table 1 presents the various levels of mabolo flesh that was used in the study.

Table 1. Varying levels of mabolo flesh in tart filling production

\begin{tabular}{cc}
\hline Treatment & $\begin{array}{c}\text { Mabolo Flesh } \\
(\% \mathrm{w} / \mathrm{w})\end{array}$ \\
\hline 1 & 0 \\
2 & 15 \\
3 & 30 \\
4 & 45 \\
5 & 60 \\
6 & 75
\end{tabular}

PqOqh"tgr hecvkp"?"4

\section{Sensory Evaluation}

The mabolo tart filling was subjected to sensory evaluation to determine the effect of mabolo flesh on the sensory attributes of the product. Color, aroma, taste, flavor, texture and overall acceptability were the sensory attributes evaluated using descriptive scoring and 9-point Hedonic scale. The evaluation was done by 64 sensory panelists at the sensory evaluation room of the Department of Food Science and Technology (DFST), Visayas State University (VSU), Visca, Baybay City, Leyte.

\section{Statistical Analysis}

Data were statistically analyzed using a one-way analysis of variance (ANOVA) to establish significant differences between mean values at significance level using 
Microsoft Excel version 2010. Significantly different results were further analyzed using Tukey's HSD Test to determine further which groups in the samples differ significantly.

The determination of the optimum formulation was done using Regression Analysis in 2nd-degree polynomial using Microsoft Exce $^{\mathrm{Tm}}$. Point of the lines that intersected with each other was identified as the candidate optimum.

\section{RESULTS AND DISCUSSIONS}

\section{Sensory Evaluation}

Sensory analysis of food is examined with the human senses. It determines the organoleptic properties of the product and the enjoyment of the consumers towards the products. Sensory testing aims to describe the product's quality characteristics.

\section{Effect on Color}

The color of the product often depends on the ingredients used. The color of the mabolo tart filling was brown, as described by $31.5 \%$ of the respondents, while $22.7 \%$ described it as having a lighter color (light brown). The mean acceptability of tarts without mabolo in the filling $\left(T_{1}\right)$ and those with $15 \%$ mabolo flesh $\left(T_{2}\right)$ were 7.67 and 7.50, respectively (Table 3 ). The lowest color acceptability rating was perceived for tarts with $45 \%$ mabolo flesh $\left(T_{4}\right)(7.07)$. However, it should be noted that the forenamed treatment is not significantly different from the rest of the tart products (except $\mathrm{T}_{1}$ ) (Table 3 ). Mean acceptability values were high, which all correspond to 'like moderately' on the 9-point Hedonic scale.

With reference to judges' perception towards individual treatment samples, the panelists described the color of tart without mabolo flesh $\left(T_{1}\right)$ as yellowish-brown, while the color of tart containing $75 \%$ mabolo flesh $\left(T_{6}\right)$ was described as brown (Table 2). The flesh of raw mabolo is cream, but sugar in the presence of heat results in chemical reactions such as caramelization and Maillard browning reaction (De Rovira 2008), thereby creating a greater degree of browning at higher levels of mabolo flesh over the control $\left(T_{1}\right)$.

\section{Effect on Aroma}

The main aroma compounds in the intact mabolo fruit, pulp, and peel are esters and a-farnesene, according to Hung et al (2016). The perception of the aroma depends on the concentration of these volatiles in the product. In the experiment, the treatment samples with mabolo flesh were described as having a slightly perceptible mabolo fruit aroma $\left(T_{2}\right.$ to $\left.T_{6}\right)$. The mean aroma acceptability of the treatment samples for mabolo filling ranges from 7.20-7.57 $\left(T_{3} \& T_{5}\right)$, which do not significantly differ from the rest of the tart samples (Table 3 ). This is equivalent to 'like moderately' in the 9-point Hedonic scale. Increasing mabolo flesh to $30 \%$ decreases the aroma acceptability and raises at a $60 \%$ level of mabolo flesh (Table 3 ). Although ANOVA revealed that the utilization of mabolo flesh in the filling causes no significant effect on the aroma acceptability, it is interesting to note that increasing further to $75 \%$ could cause acceptability values for the aroma to decline. 


\section{Sensory quality of custard tart as affected by varying levels of Mabolo}

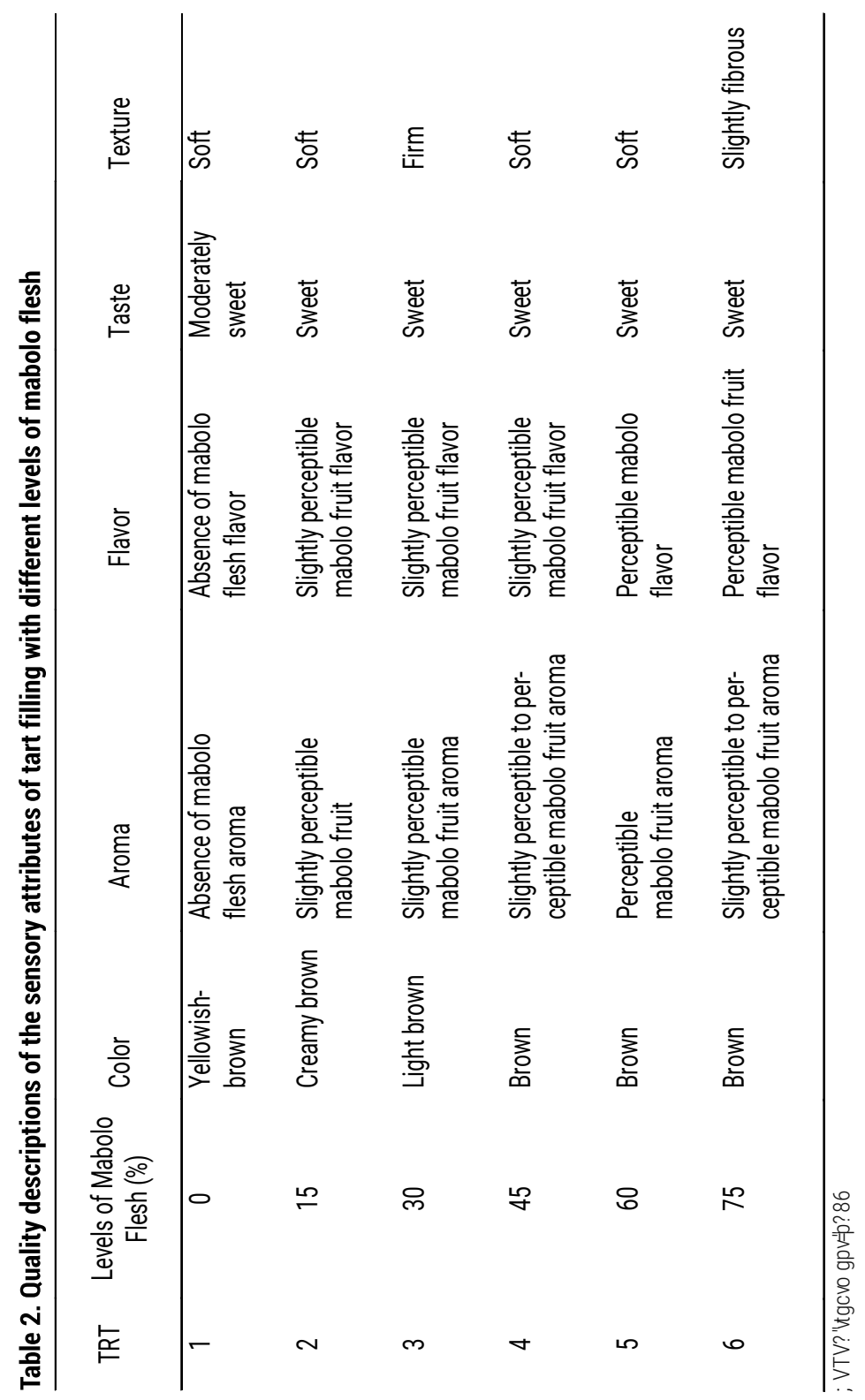




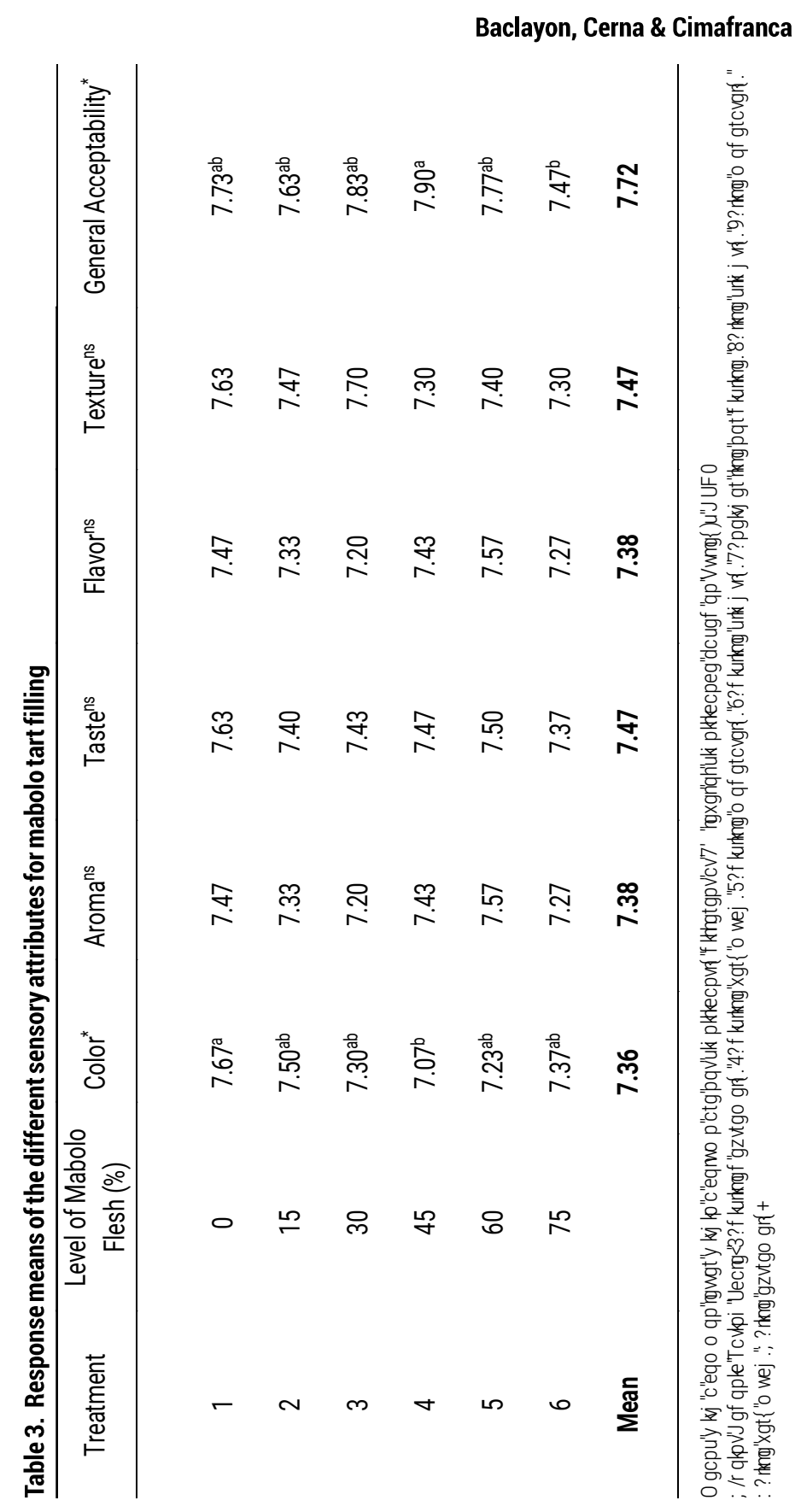




\section{Sensory quality of custard tart as affected by varying levels of Mabolo}

\section{Effect on Flavor}

According to Figoni (2008), flavor perception depends on many factors related to the product being evaluated as well as to the person doing the evaluation. One of the factors specifically identified by the forenamed author, are the ingredients used in baking. Aside from the complex flavors produced during baking as a result of chemical reactions on carbohydrates, sugars and fats in the crust, the expression of the varying levels of mabolo flesh in the filling on the flavor of the product was assessed.

In terms of flavor, the sensory panelists were able to perceive mabolo flavor in the product except for $\mathrm{T}_{1}$ (absence of mabolo flesh). Product with higher levels of mabolo flesh had a high perceptibility of mabolo flavor (Table 3). $T_{4} T_{5}$ and $T_{6}$ are distinctively described as having a very perceptible mabolo flavor as shown in Table 2. In other words, the mabolo flavor becomes profound in tarts added with 45,60 , and $75 \% \mathrm{w} / \mathrm{w}$ mabolo flesh. This is due to aromatic compounds, which are present in the mabolo pulp at more concentrated levels, being perceived by retro nasal olfaction during consumption. The condensed milk also contributed to the flavor because of the unique flavor brought about by caramelization and the Maillard reaction during the heating stage of the milk (De Rovira 2008). The mabolo fruit's characteristic flavor similar to bananas and overripe apple mixed together (Marketman 2004) also contributed to flavor of the product.

Although there was a distinguishing difference in the flavor descriptions of the filling, the ANOVA discloses that varying levels of mabolo flesh do not significantly affect the flavor acceptability of the tart (Table 3). The acceptability values that range from 7.33 to 7.63 are closely comparable, and they all fall at 'like moderately' category of the 9-point Hedonic scale.

\section{Effect on Taste}

The mabolo filling samples were described by the panelists as having a sweet taste on treatment samples with $15 \%, 30 \%, 45 \%, 60 \%$ and $75 \%(\mathrm{w} / \mathrm{w})$ mabolo flesh $\left(T_{2}\right.$ to $\left.T_{6}\right)$, whereas, $0 \%$ level of mabolo flesh was perceived with moderate sweetness (Table 2). The moderately perceived sweetness in $T_{1}$ was due purely to the condensed milk, whereas increasing the levels of mabolo flesh resulted in the decreasing sweetness of the product.

The range of acceptability values was 7.37 to 7.63 , was within the like moderately' category of the 9-point Hedonic scale (Table 3). The ANOVA, however, implied that mabolo flesh at its highest level of $75 \%$ had no consequential effect on the acceptability rating for taste.

\section{Effect on Texture}

The texture descriptions of the mabolo filling were soft, firm, and slightly fibrous (Table 2). Softness of the filling was perceived by the panelists at treatment samples $T_{1}, T_{2}, T_{4}$, and $T_{5}$, 'firm' for $T_{3}$, and 'slightly fibrous' for $T_{6}$ (Table 2). Mabolo flesh inherently possesses fibrous materials that become evident at the highest level of mabolo flesh in the product, thereby described as such. 
In terms of acceptability for texture, $T_{1}, T_{2}, T_{3}$ showed higher mean acceptability values of 7.63, 7.47, and 7.70, respectively. On the other hand, 7.30, 7.40, and 7.30 are the ratings for $T_{4}, T_{5}$, and $T_{6}$, which had slightly lower mean acceptability values. Both groups of values depict an interesting trend at the increasing level of mabolo flesh, but it shall be noted that these values are not significantly different with each other (Table 3). This means that when increasing the level of mabolo flesh up to $75 \%$, texture acceptability was statistically the same as having none. In addition, it was still liked moderately by the panelists.

\section{Effect on General Acceptability}

General acceptability is the overall acceptability of the product. $T_{4}$ got the highest mean acceptability of 7.90 . This acceptability score was statistically revealed not significantly different from $\mathrm{T}_{1}$ to $\mathrm{T}_{3}$, as well as $\mathrm{T}_{5}$, but it was statistically different from $T_{6}$ (Table 3 ). Regardless of statistical results, these values correspond to 'like moderately' on the 9-point Hedonic scale. Further, ANOVA conveyed that treatment samples with added mabolo flesh of up to $75 \%$ level in the filling were not significantly different from the control.

\section{Optimum Level of Mabolo Flesh in Mabolo Tart Filling}

Figure 2 shows that among all of the sensory attributes (from the regression), only the color and general acceptability were correlated with the changes in the levels of mabolo flesh. This is the reason why Figure 3 highlighted the critical levels of mabolo that may be expected as an optimum formulation. At $80.54 \%(\mathrm{w} / \mathrm{w})$ levels of mabolo flesh, color, and general acceptability intersected. Thus, it was discerned that this level is the optimum level of mabolo flesh in the mabolo tart filling formulation.

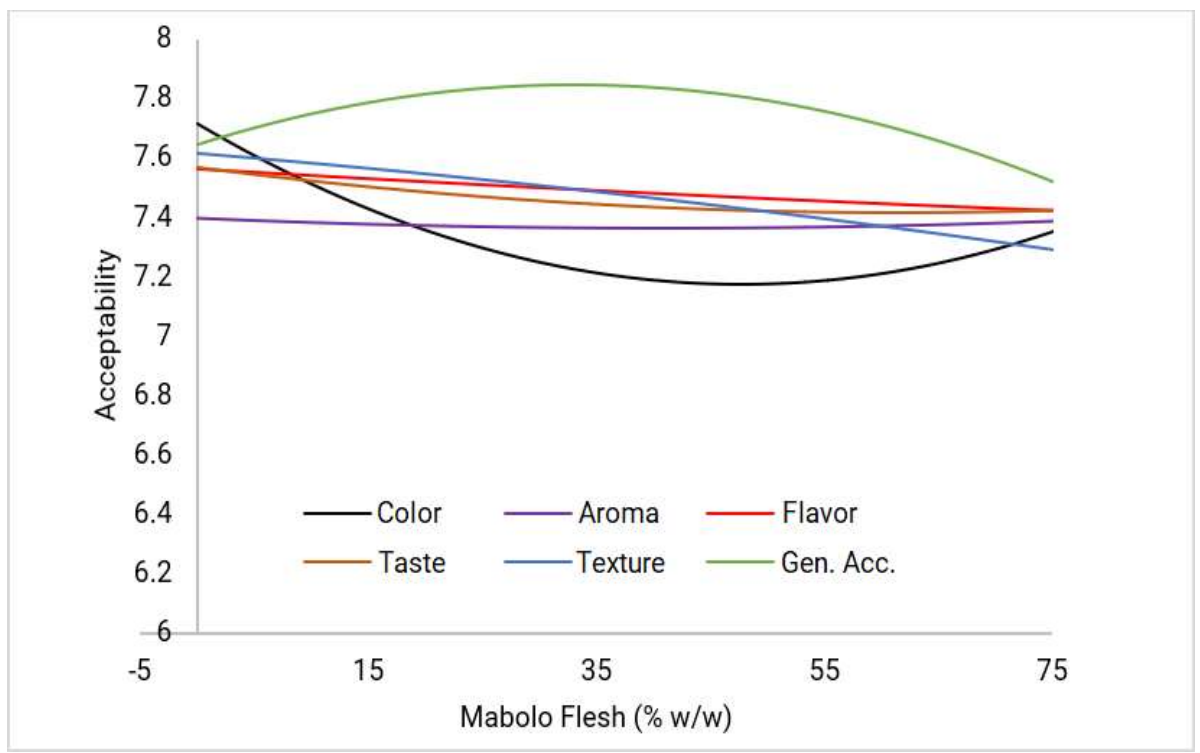

Figure 2. Superimposed graph of all sensory attributes for mabolo filling 


\section{Sensory quality of custard tart as affected by varying levels of Mabolo}

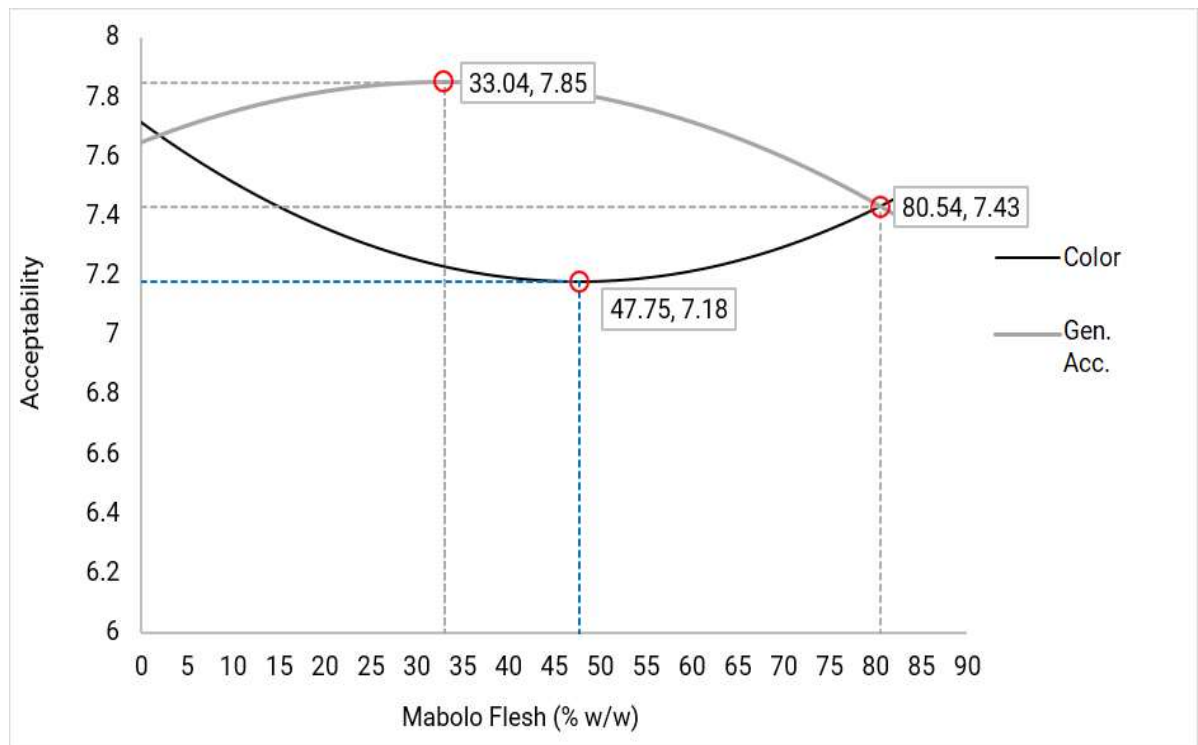

Figure 3. Optimum formulation of mabolo filling

\section{CONCLUSION}

Mabolo flesh significantly affects the color of mabolo tart filling, while the rest of the sensory quality parameters (aroma, taste, flavor, texture, \& general acceptability) were not significantly affected by the addition of mabolo flesh to the product. Tarts having $75 \%$ mabolo flesh in the filling were significantly different from the tarts with $45 \%$ mabolo flesh (in terms of general acceptability), while the control was found statistically to have the same general acceptability as samples that had mabolo flesh in the filling. The optimum formulation was $80.54 \% \mathrm{w} / \mathrm{w}$ level of mabolo flesh in the filling.

\section{REFERENCES}

De Rovira D Sr. 2008. Dictionary of flavors (2nd edn). Blackwell Publishing, USA Figoni PI. 2010. How Baking Works: Exploring the Fundamentals of Baking Science. John Wiley \& Sons, Inc., Hoboken, New Jersey

Haque MN, Saha BK, Karim MR \& Bhuiyan MNH. 2009. Evaluation of Nutritional and Physico-chemical Properties of Several Selected Fruits in Bangladesh. Bangladesh Journal of Scientific and Industrial Research 44(3):353-358

Hung SF, Roan SF, Chang TL, King HB \& Chen IZ. 2016. Analysis of aroma compounds and nutrient contents of mabolo (Diospyros blancoi A. DC) is an ethnobotanical fruit of Austronesian Taiwan. Journal of Food and Drug Analysis 24(1):83-89

Maridass MG, Ghanthikumar S \& Raju G. 2008. Preliminary phytochemical- analysis of Diospyros Species. Ethnobotanical Leaflets 12:868-72

Marketman. 2004. MARKETMANILA.COM. http://www.marketmanila.com /archives/mabolo-kamagong 


\section{Baclayon, Cerna \& Cimafranca}

Pobar RA. 2013. Enhancing the use of value-added products from underutilized fruit of the endangered mabolo (Diospyros blancoi). International Journal of Environmental and Rural Development (4-1):100-105

Yadav M, Srilekha K, Mrunal BD \& Maheswari KU. 2018. Potential health benefit of underutilized fruits: A review. Journal of Pharmacognosy and Phytochemistry 7(5):1417-1420 